\title{
Informal talks about writing as a constructive way to develop young L2 learner print awareness
}

\begin{abstract}
The article examines the possibilities of fostering young L2 learner print awareness via teaching for conversing about and reflecting on writing. In order to achieve this goal the present author conducted the qualitative research on a group of 2 nd-graders engaged in the performance of a series of open-ended L2 written tasks accompanied by L1 cues. The analysis of collected data shows that drawing children's conscious attention to writing might encourage the constructive transferability of linguistic skills from L1 to L2, thus being conducive to the development of logical thinking necessary for the enhancement of their print awareness.
\end{abstract}

KEYWORDS: print awareness; dialogical approach; L2 written code; L2 written tasks

\section{INTRODUCTION}

Young learner development is a perpetually intriguing, multifaceted phenomenon understood as an asymmetrical combination of perceptual, linguistic, affective and motor processes. As such, it is muffled in numerous assumptions, theories and conceptions worked out by various outstanding authors (e.g. Bruner 1996, Chomsky 1968, Gombert 1992, Kephart 1979, Krashen / Terrell 1995, Montessori 2003 [1948], Piaget 1952 [1936], Sternberg / Spear-Swerling 1996, van Kleeck 1982, Vygotsky 1997 [1934]) aiming to shed light on some of the complexities of child functioning. While a lot has been said about children's engagement in concrete operations, formulaic assimilation of language, natural propensity for language acquisition, extralinguistic acuity, listening and speaking skills, linguistic creativity, internalisation of language, anticipation of external rewards or need for learning by doing, relatively little attention has been paid to the role of metalinguistic knowledge and print awareness in accelerating child intellectual growth in gener$\mathrm{al}$ and fostering the ability to write in particular. In other words, perceiving 
children as playful and inventive learners, perfect imitators or adept users of implicit knowledge seems to dominate a tendency to view them as reflective analysts and symbolists ready to switch from knowledge-telling to knowledge-transforming behaviours. This is why the current study is concerned with examining the opportunities for developing print awareness by inspiring children to ponder related concepts and make their own inquiries, guesses, inferences or discoveries.

\section{WHAT IS PRINT AWARENESS?}

Print awareness is a multidimensional component of language awareness regarded, together with word awareness and phonological awareness, as a strong determinant of early reading achievement (Adams 1990, Justice / Ezell 2001) contributing to child general metalinguistic development (Gombert 1992). Since there are a variety of narrower or broader characteristics of print awareness whose authors tend to single out and concentrate on particular features of this skill, it seems worthwhile to systematise them. As for narrower definitions, they highlight print awareness as the ability to realise that written language and oral language are interrelated, that print has different functions and is governed by a finite set of conventional rules (Hiebert 1981, Goodman 1986) and also as readiness to understand the directionality principle (Justice / Ezell, 2001) or reading-related terminology (Clay 1979). As far as a wider perspective on print awareness is concerned, it includes a child's understanding of the concepts of print, reading and writing, a child's awareness of his/her own reading/writing abilities and the awareness of a foreign language as differing from a child's mother tongue yet performing similar functions (Krasowicz-Kupis 2004).

As for the stance on print awareness to be taken in the present study, I decided to jointly revise the two aforementioned perspectives and as a result propose my own understanding of the said concept as the interplay of the following factors:

- child ability to understand print concept,

- child ability to understand print functions,

- child ability to understand the essence of writing as an activity,

- child ability to understand the discrepancies between two different writing systems,

- child ability to understand and operate related terminology.

It has to be stressed that the above specification was made with more respect to writing than noticed in many existing definitions of print awareness 
which favour reading (Adams 1990, Clay 1979, Hiebert 1981), whereas writing remains in them an underestimated part of literacy, the same case being with teaching this skill in young learner L2 classroom (Gillen / Hall 2003). In order to counterbalance this tendency in the present study it is assumed that print awareness underlies the process of learning to write that cannot proceed successfully without understanding print functions, knowing basic writing conventions or differentiating between them in L1 and L2.

\section{THE DIALOGICAL APPROACH AND ITS PLACE WITHIN L2 EDUCATION}

An interesting opportunity for raising young learner awareness of his/her own abilities and knowledge is offered by Sternberg (Sternberg / Spear-Swerling, 1996) in the Dialogical Approach as a tool of developing the art of asking and answering questions, some of its principles deserving to be transmitted to the area of L2 education.

The Dialogical Approach, referring to Vygotsky's (1997) [1934] social constructivism with its idea of arranging for the young to rediscover and 'acquire the accumulated artifacts of the group or culture' (Moll, 2005: 262), is meant to teach for thinking in an argumentative way through sensitising children to the inferential power of teacher and peer assistance likely to broaden their zone of proximal development and therefore make it possible for them to solve more and more difficult problems. Teacher guidance consists in offering affect-creating cues to be intertwined with comments exchanged by learners themselves. To be more precise, the Dialogical Approach builds upon both teacher- and learner-asked open-ended questions (e.g. "What's your opinion of...?", "What's the relationship between...?", "Why are you in favour of...?", "What makes you think like that?", "What facts/events/objects are of greatest importance for you?", "Why can't we...?", "Can you give us examples of...?", "Is it possible to...?") as conducive to lively and exploratory classroom discussions revolving around topics connected with particular school subjects. Thus, as indicated by Sternberg and Spear-Swerling (1996), it is recommendable that apart from asking their own questions, teachers welcome children's questions for they naturally release a logical expression of curiosity about the world, which is a prerequisite for formulating and testing out different hypotheses. Accordingly, the said authors promote collaborative, trial-and-error learning expected to help children to look at things through meaningful others' eyes and take advantage of meaningful others' experiences. 
The implications of the Dialogical Approach for this study refer to the present author's assumption that it is possible to develop child print awareness via teaching for thinking and talking about writing and literacy with reliance on L1 cues supposed to underpin children's engagement in doing L2 written tasks. The proposed cues are expected to enable learning synergy based on negotiating social worlds of literacy for the purpose of arriving at common conclusions.

\section{THE PRESENT STUDY - INTRODUCTORY REMARKS}

The study is meant to face up to a stereotyped view that simultaneous writing in L1 and L2 might be a tiring and annoying experience for children who might find it difficult to distinguish between two different writing systems (Komorowska 2005). It is generally believed that since they have not yet fully mastered writing in L1, writing in L2 might go beyond their actual abilities, thus temporarily becoming an unattainable idea. This is why in young learner L2 pedagogy the emphasis is laid on teaching listening and speaking as communication skills naturally developing within a child before puberty (Asher 2003, Krashen / Terrell 1995). However, the research data collected by the authors concerned with young learner literacy (Bialystok 2002, Datta 2007, Kenner / Gregory 2003) to stand in clear opposition to this conviction for which reason it is planned to show that writing in L2 while still learning to write in L1 might amount to double enjoyment as well as cognitive and linguistic challenge for children.

The study is intended to examine the extent to which the dialogically underpinned L1 cues might give an opportunity for informal talking about writing with its advantages, functions, rules and intricacies. The cues in question are to enable research subjects to both playfully and meaningfully switch from epi-processes to meta-processes connected with a deeper and deeper understanding of various features and properties of writing.

\subsection{Research goals}

(1) To investigate the role of informal talks about writing in enhancing child print awareness. For the purpose of this article informal talks can be defined as the talks which are not fully structured and as such they are guided by the subjects' responses likely to determine the nature of questions to follow.

(2) To document the children's constructive engagement in the dialogically supported performance of L2 written tasks. Constructive engagement 
is understood as the interplay of young learner imaginative thinking, original ideas and sensitivity to L2 written code in the process of performing L2 written tasks.

\subsection{Participants}

The research was conducted on a group of twenty Polish $2^{\text {nd }}$-graders who participated in ten 45-minute sessions devoted to L2 writing initially preceded by and gradually more and more tightly intertwined with informal chats about writing. They had two lessons per week, so the whole study extended over the length of five weeks. While working with the subjects, the present author as the teacher-researcher endeavoured to use the dialogically underpinned L1 cues as the instrument preparing for and gently accompanying the performance of eight L2 written tasks belonging to five categories (name exploring, copying, word synthesising, writing light verses, writing short letters) with an intention to make it a challenging as well as enjoyable undertaking. The said tasks are an integral part of the present author's heuristico-operational model of L2 writing instruction (Zawodniak 2009) which approaches children as both inventive and imitative learners of the written code, inspired to logically observe and joyfully explore its features.

\subsection{Data collection instruments}

The research data were gathered through the observation of the children's L2 behaviours including individual and negotiated judgements about print and writing, all of them having been recorded and transcribed. The observation of the children's performance was completed with the detailed field notes which enabled the author to provide the explanatory discussion of obtained results.

\section{FINDINGS AND DISCUSSION}

\subsection{Observation of chats about print and writing}

Overall, in response to teacher-researcher cues the children made 58 logical remarks about print and writing (see Table 1) which took place either before or during the performance of seven above mentioned written tasks. 
Table 1. Quantitative and qualitative display of the children's remarks about print and writng

\begin{tabular}{|c|l|l|}
\hline $\begin{array}{c}\text { Number } \\
\text { of responsive } \\
\text { remarks }\end{array}$ & \multicolumn{1}{|c|}{ Type of responsive remarks } & \multicolumn{1}{|c|}{ Examples } \\
\hline 18 & $\begin{array}{l}\text { ・ generating principle } \\
\text { double letters } \\
\text { - onomatopoeic properties of words }\end{array}$ & $\begin{array}{l}\text { ・ glass/gas, net/ten, chair/car } \\
\text { - wash/watch, eyelash }\end{array}$ \\
\hline 16 & $\begin{array}{l}\text { - instructing peers or answering their } \\
\text { questions } \\
\text { exchanging a written work with } \\
\text { a friend and correcting it }\end{array}$ & $\begin{array}{l}\text { Saxon Genitive, spelling } \\
\text { (e.g. pencil, book, small, toy) }\end{array}$ \\
\hline 11 & the understanding of print concept & a link between written and spoken words \\
\hline 7 & L1 vs. L2 writing systems & balloon/balon, boots/buty, colour/ kolor \\
\hline 6 & related terminology & write/word/letter/apostrophe \\
\hline \multicolumn{2}{|c|}{58 logical remarks about print and writing } \\
\hline
\end{tabular}

\subsection{Talking about print concept}

With teacher-researcher guidance the children managed to accumulate and systematise various ideas (e.g. print as a collection of words and sentences which can be found in copybooks and books, linguistic difficulty as determined by word length and spelling/pronouncing characteristics) which brought them closer to the understanding of the contrasting properties of spoken/written language on the one hand and of their mother tongue and target language on the other. They joyfully searched for different words and analysed them to conclude that in English there is a wider discrepancy between the spoken and written code than in Polish. Teacher-researcher questions were joined by learner questions which revealed a growing curiosity about the English writing system in relation to speaking and the emerging awareness of the rules underlying correct spelling.

\subsection{Talking about print functions}

When asked what they needed print for, the children started to recall various situations in which they had found it useful and important. Some of them admitted that using print enabled them to become doctors and write medical prescriptions for their toy patients or to become conductors and write train tickets. Other children mentioned a possibility of making their own shopping lists, identity cards or diplomas for doing something quite unique like winning a swimming competition. Many subjects seemed to 
have established a close link between writing and drawing as they claimed that the former might serve to caption pictures or to make funny comments as part of a comic. A few children remarked that they had happened to use print as the consequence of having decided to ask their parents for something special like buying a bicycle or a dolls' house; they hoped that a written message would appear more attractive and convincing, which can be regarded as being indicative of their perception of print as a persuasive tool of expressing their dreams, wishes and expectations. Finally, for many children print was helpful in communicating with Santa Claus and Easter Bunny (writing a request for gifts) as well as with their favourite book or cartoon characters (writing an invitation to a Birthday party).

\subsection{Talking about writing as an activity}

The majority of learners referred to writing as an enjoyable though difficult activity the mastery of which would allow them to reach the world of adults. A few of them admitted that as little children they had taken pleasure in watching their parents or older siblings write and in imitating them by holding a pen and using it to fill empty sheets of paper with lines and dots. They added that those symbolic signs carried some kind of secret information (e.g. a letter to a fairy, a ticket to Venus, a restaurant bill) that could not be easily decoded by everyone. Many children asserted that writing is nicer than speaking because they can see and touch it, look at it anytime they want to and also take it home to proudly show to their family members, which implies that they treated writing as the important material evidence of their abilities and progress deserving approval or even admiration. The children remarked that writing is similar to drawing (some of them defining writing as drawing words) because both activities involve skilful hand movements and the use of a variety of pens and pencils. They also made a comment that there are people who scribble rather than write, which makes their works difficult to read. Furthermore, a few subjects stated that writing not always pays off since the errors that might be made will not pass unnoticed, thus entailing a lower grade and no teacher/parent enthusiasm.

\subsection{Talking about the differences between $L 1$ and $L 2$ writing systems}

In response to the question about what makes the English and Polish writing systems different, the children eagerly went over the already done written tasks and L2 textbook, some of them, presumably for comparative reasons, 
also looking into their L1 materials. As the result, they noticed the letters occurring much more frequently in English than in Polish (e.g. $q, v)$ as well as the ones never occurring in English (e.g. ś, $\dot{z}, \ell$ ). Besides, they paid attention to a considerable, compared to English, length of Polish words quite often functioning as long equivalents of much shorter L2 lexical items (e.g. "kucharz" "cook", "kubek" - "mug", "książka" - "book", "samochód" - "car"). Some of the subjects remarked that unlike Polish, in English it is possible to learn only one word to refer to both genders (e.g. "friend", "teacher"). The children also asserted that in English there are more words likely to be confused (e.g. "watch" - "wash") and that many English words contain doubled letters which are pronounced as one (e.g. "slipper" "boots", "balloon", "tall"). It is finally worthwhile to mention one boy who said that he had heard of foreigners writing from right to left, the remark arousing other children's interest and causing the teacher-researcher to explain the concept of directionality.

\subsection{Talking about related terminology}

The teacher-researcher tried to acquaint the learners with such terms as "write" /"writing", "word", "letter" and "apostrophe". They made an interesting analysis of the word "write" claiming that its spelling is equally complex and tricky as the activity itself; they were genuinely involved in looking for similar sounding words (e.g. "bright", "night", "kite", "Sprite") and negotiating the degree of their visual resemblance to "write". The subjects maintained that it would be easy for them to remember "word" since they had already known it as a software package. Their curiosity was also excited by "letter" owing to its double meaning, which is not the case in Polish; they even engaged in creating funny sentences like "My letter is better" or "This letter has many letters". As regards the concept of apostrophe, an attempt was made to appeal to the children's imaginative perception of L1/L2 writing conventions and tell them that in English the owner always dominates his/her belongings, which is marked by the apostrophe inserted into the space between the former and the latter. The subjects remembered the word "apostrophe" as something unique because they imagined that it empowered the owner to possess whatever he/she was dreaming of. Since the Polish equivalent of the said word is very similar ("apostrof"), they used L1/L2 terms interchangeably and it seems that a vivid explanation they had been provided with enabled them to move more confidently between concrete settings and abstract ideas. Another advantage of having appealed to the learners' imagination was their spontaneous wish to write short descriptions of their friends' / family members' possessions. 


\subsection{L2 written task performance}

The children willingly participated in the written tasks pooling ideas about print and writing, creating stories or looking for their own ways of discovering new words.

The subjects enjoyed working with their names, searching their memory for already learned words and making exploratory guesses. They were so delighted that Polish names provided the opportunity for constructing English words that they wanted to compete and check whose name was the richest reservoir of $\mathrm{L} 2$ lexical items. The children also made attempts to generate words common to combined Polish and English names (e.g. Ewa/Mark - wake, Basia/Ken - bike). Finally, they wanted to find out what unknown words had been hidden in their names and asked the teacherresearcher to write them on the blackboard (e.g. Marysia - May, ram; Bartek - bake). Playing with their own and their colleagues' names enabled the children to understand the generating principle and thus realise that a limited number of letters can be used for creating a variety of words.

As the result of having been asked to point out the most difficult words and make sentences with them, the children argued about what qualifies words as difficult (word length, discrepancy between oral and written forms of English words, lack of similar sounding L1 equivalents). The pupils were enthusiastic about the idea of creating their own story whose details, i.e. sizes, quantities, colours, were to be collaboratively agreed on. They willingly took to copying the finished story and were very careful not to make spelling errors as well as ready to help some of their classmates by attracting their attention to certain structural details of rewritten words (e.g. the second $r$ in "squirrel" or $v$ instead of $w$ in "favourite").

The children enjoyed being put in the position of discoverers of new words, which made them excited and curious about the final outcome. The need to seek single letters within illustrated words motivated the subjects to write these down as wholes and check their spelling by consulting the dictionary, looking into their notes or using teacher-researcher cues which reminded them of similar words (e.g. "pear" - "wear", "house" - "mouse"). They took pleasure in examining the newly discovered words ("slipper", "hood", "boots"); they noticed doubled letters and juxtaposed "slipper" with "sleep", which, followed by a few successful attempts to construct funny sentences (e.g. "I never sleep in slippers"), led the teacher-researcher to acquaint them with the words "sleepy" and "sleepyhead"

Most of the children managed to combine illustrated words into rhyming pairs and create nice light verses (e.g. "Honey, where's your money?", "Give my parrot one carrot", "Green parrots eat blue carrots") which were written 
by little poets on the blackboard and compared. Answering teacherresearcher question about the words they perceived as most tricky, the subjects argued for "money" /"honey" due to what they referred to as the hidden "e", and for "rug" /"mug" due to " $\mathrm{u}$ " / $\Lambda$ / which they characterised as sounding very strange, the judgement probably resulting from the fact that no such vowel exists in Polish. The learners decided to look for more similar words (e.g. "fun", "sun", "nut", "but") and were a bit annoyed that not all of them (e.g. "put") were pronounced the same. A few children once again tried to use the generating principle and create new words (e.g. "carrot" "car", "rat"; "coat" - "cat"), which was an enjoyable work for them.

The children were also given the opportunity to tell the teacherresearcher about their L2 learning experience with respect to what they perceived as their strengths and weaknesses. In many cases they made lists of familiar words some of which were systematised as members of larger classes of objects (e.g. furniture, foodstuffs, fruits, days of the week). They wanted to inform that, for instance, they understood the relationship between the English owner and his/her belongings (Saxon Genitive), that they were able to recombine different letters into new lexical items (the generating principle), that they confused the spellings of certain words (e.g. "Tuesday" /"Thursday", "wear" /"where"), that they could create light verses or that they liked discovering new words. There were also some children who admitted that they would like to reverse roles with the teacher-researcher so that they could correct their classmates' written work.

\section{CONCLUSION}

The above described research shows that informal chats about print and writing might arouse young learner interest in L2 written code and contribute to his/her reflective assimilation of its basic features. A gentle, indirect, question-based assistance seems to have attracted the learners' conscious attention to the role of print in their everyday lives as well as to writing as an activity likely to help them to establish closer approximations to the world of adults. Class discussions enabled the children to look at L2 writing from L1 perspective which made them more observant learners in terms of word structure, spelling or speaking/writing relationship. The learners were constructively engaged in working on the proposed L2 written tasks which required and at the same time encouraged a joint investment of their imagination, L2 experience and curiosity in seeking the best and most interesting solutions. The opportunity for collaborative work together with a favourable climate for open-ended work entailed the children's' own discoveries, ques- 
tions, inferential guesses and inventive initiatives which, in all likelihood, permeated and reinforced their zone of proximal L2 writing development, thus enabling them to joyfully learn about the written language and its properties. It can, therefore, be affirmed that the research goals have been achieved, which makes it reasonable to highlight dialogically organised talks about various aspects of writing as having the potential for developing young learner print awareness with respect to the child-specific power of imagination and inquiring attitude to the language.

\section{REFERENCES}

Adams, M.J., 1990. Beginning to read: Thinking and learning about print. Cambridge, MA: MIT Press.

Asher, J.J., 2003. Learning another language through actions. Los Gatos, CA: Sky Oaks Productions.

Bialystok, E., 2002. Acquisition of literacy in bilingual children: A framework for research. In: Language Learning 52 (1), 159-199.

Bruner, J., 1996. The culture of education. Cambridge, MA: Harvard University Press.

Chomsky, N., 1968. Language and mind. New York: Hartcourt, Brace \& World.

Clay, M., 1979. The early detection of reading difficulties: A diagnostic survey with recovery procedures. Tadworth: Windmill Press.

Datta, M., 2007. Bilinguality and literacy: Principles and practice. London: Continuum.

Gillen, J. / Hall, N. 2003. The emergence of early childhood literacy. In: Hall, N. / Larson, J. / J. Marsh, J. (Eds.), Handbook of early childhood literacy. London: Sage, 3-12.

Gombert, J.E., 1992. Metalinguistic development. London: Harvester-Wheatsheaf.

Goodman, K.S., 1986. What's whole in whole language? Portsmouth, NH: Heinemann.

Hiebert, E, 1981. Developmental patterns and interrelationships of preschool children's print awareness. In: Reading Research Quarterly, 16, 236-260.

Justice, L.M. / Ezell, H.K., 2001. Word and print awareness in 4-year-old children. In: Child Language Teaching Therapy, 17, 207-225.

Kenner, C. / Gregory, E., 2003. Becoming biliterate. In: Hall, N. / Larson, J. / Marsh, J. (Eds.), Handbook of early childhood literacy. London: Sage, 178-188.

Kephart, N.C., 1979. The slow learner in the classroom. Columbus, OH: Merrill, Ayres.

Komorowska, H., 2005. Metodyka nauczania jezzyków obcych [Foreign language teaching methodology]. Warszawa: Fraszka Edukacyjna.

Krashen, S. / Terrell, T.D., 1995. The Natural Approach: Language acquisition in the classroom. Hemel Hempstead, Hertfordshire: Phoenix ELT.

Krasowicz-Kupis, G., 2004. Rozwój świadomości językowej dziecka: Teoria i praktyka [The development of child language awareness: Theory and practice]. Lublin: Wydawnictwo Uniwersytetu Marii Curie-Skłodowskiej.

Moll, L.C., 2005. Inspired by Vygotsky: Ethnographic experiments in education. In: Lee, C.D. / Smagorinsky, P. (Eds.), Vygotskian perspectives on literacy research: Constructing meaning through collaborative inquiry. Cambridge: Cambridge University Press, 256-268.

Montessori, M., 2003 [1948]. To educate the human potential. Oxford: Clio Press. 
Piaget, J., 1952 [1936]. The origins of intelligence in children. New York: International Universities Press.

Sternberg, R.J. / Spear-Swerling, L., 1996. Teaching for Thinking. Washington, DC: The American Psychological Association.

Van Kleeck, A., 1982. The emergence of linguistic awareness: A cognitive framework. In: Merrill-Palmer Quarterly, 28, 237-265.

Vygotsky, L.S., 1997 [1934]. Thought and language. Cambridge, MA: MIT Press.

Zawodniak, J., 2009. Rozwijanie sprawności pisania w dydaktyce językowej na etapie Wczesnoszkolnym. Zielona Góra: Uniwersytet Zielonogórski. 